\title{
DIVISION II / IAU REPRESENTATIVE REPORT INTERNATIONAL HELIOPHYSICAL YEAR
}

REPRESENTATIVE

TRIENNIAL REPORT 2006 - 2009

\author{
David F. Webb
}

\section{Introduction}

The International Heliophysical Year (IHY) is an international program of scientific research and collaboration to understand the external drivers of the space environment and climate. Its activities were centered on the year 2008, the 50th anniversary of the International Geophysical Year. The IHY involves utilizing the existing assets from space and ground as a distributed Great Observatory and the deployment of new instrumentation, new observations from the ground and in space, and public and student education. The IHY officially was launched in February 2007 with an opening ceremony and workshop in Vienna. Many IHY activities, both scientific and educational, have occurred since then. In practice, these activities have taken place over the last several years, and the programs that have been established through the IHY will continue into the future as 'legacies' of the IHY.

\section{IHY Activities}

Within the IAU, coordination of IHY activities is within Division II Sun and $\mathrm{He}$ liosphere, whose current president is Donald B. Melrose. David F. Webb is the IAU Representative to the IHY and Natchimuthuk Gopalswamy is the chair of the IHY subgroup within the IAU Working Group for International Collaboration on Space Weather (ICSW). Hans J. Haubold leads the IHY effort for the United Nations under the auspices of COPUOS and the UN Basic Space Science program. At the Prague General Assembly the IHY held a working group meeting as part of the ICSW WG and presented several talks in a sub-session of SpS5 on Astronomy in Developing Countries.

\subsection{IHY science}

IHY science is organized through science working groups that coordinate analysis and modeling efforts, and are responsible for planning IHY meetings, symposia and workshops through three major thrusts: scientific observing campaigns known as the Coordinated Investigation Programs (CIPs), data analysis workshops, scientific meetings and publications, and public outreach. The IHY Secretariat in Washington, D.C., USA, provides international coordination, produces newsletters, maintains the IHY website at <www.ihy2007.org/>, writes articles, coordinates media affairs, and develops outreach products. An important, recent CIP campaign is the Whole Heliosphere Interval (WHI) that occurred over one solar rotation, from 20 March - 16 April 2008. WHI is an international coordinated observing and modeling effort to characterize the 3-D interconnected solar-heliospheric-planetary system. The first WHI workshop (on Data Assessment and 
Modeling) was held in Boulder, CO, USA, in August 2008. Next year the results from WHI will be presented at a science workshop as well as at other meetings and a journal special issue is planned. In addition, WHI will be the focus of JD16 at the IAU XXVII GA in Rio de Janeiro, August 2009, called IHY Global Campaign - Whole Heliosphere Interval. Details on WHI including data sets are at: <ihy2007.org/WHI/WHI . shtml>.

Another part of IHY science is the cooperative initiative with the UNBSS program, through which the IHY assists in deploying arrays of small instruments to make global measurements. Fifteen instrument concepts have been developed and have been or are being deployed. These include a network of radio telescopes to observe CME-related radio bursts, chains of magnetometer arrays to observed magnetic activity, and hundreds of GPS receivers to observe the ionosphere. See: <ihy2007.org/observatory/observatory . shtml>. These systems have been discussed at annual IHY-UN UNBSS workshops in the United Arab Emirates (2005), Bangalore, India (2006), Tokyo, Japan (2007) and Sozopol, Bulgaria (2008). The last workshop will be held on Jejn Island in South Korea in September 2009. The IAU is a cosponsor of all of these meetings.

\subsection{IHY science meetings and workshops}

Many scientific meetings and workshops related to IHY have been held in 2007-2008 in countries including France, India, Germany, Bulgaria, Austria, Mexico, Italy, Ethiopia and Russia. Several are highlighted here. The first major European IHY conference The Sun, the Heliosphere, and the Earth was held in Bad Honnef, Germany, May 2007. The World Space Week was celebrated worldwide in October 2007 with the Sputnik 50th Anniversary Celebration and Symposium. The Second IHY SCINDA Workshop and IHY-Africa Space Weather Science and Education Workshop were held in Addis Ababa, Ethiopia in November 2007. The International IHY Symposium and Sputnik 50th Anniversary Celebration was held in Zvenigorod, Moscow, Russia in November 2007. IHY themes were involved in two regional African meetings in Cairo in 2008: the first Middle East-Africa Regional IAU Meeting (MEARIM) in April and the IAGA International Symposium Space Weather and its Effects on Spacecraft in October. IAU Symposium No. 257, involving IHY science topics and called Universal Heliophysical Processes, was held 15-19 September 2008 in Ioannina, Greece. See: 〈iau257.uoi.gr>. The organizers were N. Gopalswamy, D. F. Webb, K. Shibata and A. Nindos.

Future IHY meetings include an AGU Chapman Conference on Universal Processes to be held in Savannah, GA, USA, 10-14 November 2008 and organized by Nancy Crooker and Marina Galand. At this same time a symposium on 50 years after the IGY will be held in Japan organized by M. Kono, T. Iyemori and K. Yumoto, and a European IHY meeting Heliosphere and its Environment will be held at ISSI in Bern, Switzerland. Finally, the IHY-Africa 2009 Workshop will be the final official IHY workshop. It is to be held in Livingstone, Zambia in June 2009. IHY special sessions have also been organized at many periodic scientific meetings, including COSPAR, AGU, EGS, IUGG, SHINE, and SORCE.

\subsection{IHY outreach}

IHY Outreach activities include spreading knowledge of space science and exploration to the public and inspiring the next generation of space scientists, and are led by Cristina Rabello-Soares. There are now outreach coordinators in 25 countries. In Thailand an IHY booth was set up by the Thai IHY group during the annual Science and Technology Fair in Bang Na 8-18 August 2007 that was attended by about 1 million students. The Center for Science Education at the University of California, Berkeley, and the 
Stanford Solar Center sponsored special web-based activities to celebrate World Space Week and the 50th Anniversary of the Sputnik Launch, October 2007. They also hosted an IHY Space Weather Monitor workshop at the IHY-Africa Space Weather Science and Education Workshop in Ethiopia in November 2007. They demonstrated Sudden Ionospheric Disturbance instruments that track changes to the Earth's ionosphere caused by solar activity. These are targeted to high school students, and are being distributed world-wide as part of the IHY International Education Program. IHY also supported the Geophysical Information for Teachers (GIFT) Workshop The International Heliophysical Year at Addis Ababa, Ethiopia, on 10 November 2007. More recent events included Solar Week 2008 and NASA's Sun-Earth Day in March 2008 and the annual Yuri's Night Space Party on 12 April 2008. A touring art exhibit on the Sun was established at Goddard Space Flight Center in Greenbelt, MD, USA and is called Sunworks. It was first displayed in Vienna at the opening ceremony of the IHY, and is currently touring the U.S.

\subsection{IHY schools}

Part of the IHY Outreach effort is the IHY Schools Program which is assisting with five schools in 2007-2008. The purpose of these schools is to educate students about heliophysics and Universal Processes. Updated information on the schools program is at: <ihy2007.org/outreach/ihy_schools.shtml>. The first school was held in JulyAugust 2007 and co-sponsored by NASA's Living With a Star program and IHY as the North America IHY School. 34 students attended the school, 14 from countries outside the U.S., with 25 lecturers and lab coordinators participating. The first Asia-Pacific School was held at the Indian Institute of Astrophysics (IIA), Bangalore, India, 10-22 December 2007. It was an intensive two-week course on heliophysics topics with about 50 students attending. The first IHY Latin America School was held 14-20 February, 2008, and organized by CRAAM and held at the Presbyterian Mackenzie University in Sao Paulo, Brazil. About 80 students attended. The fourth school is also the second Asia-Pacific school and is planned for 20-31 October 2008 in Beijing, China. The last school, for Africa and Europe, will be held at the Centre for Basic Space Science, National Space Research and Development Agency (NASRDA), the University of Nigeria, Nsukka., Nigeria on 10-22 November 2008. These schools have been very successful and have helped to educate students and spread new knowledge about heliophysics and Universal Processes throughout the world.

\subsection{IHY Gold History}

Finally, the IHY Gold History initiative has the goals of identifying and recognizing participants in the first IGY, preserving memoirs, etc., of historical significance for the IGY, making them available to historians and researchers, spreading awareness of the history of geophysics, and planning special events. The first of these was the 'IGY+50' Celebration at the IUGG meeting in Perugia, Italy, 2-13 July 2007. During the IHY session at the 2007 Solar Extreme Events meeting in Athens, Greece, Nat Gopalswamy presented an overview talk on IHY activities. Over 200 individuals have now been recognized as members in the IHY Gold Club. 